\title{
Autoimmune Thyroiditis as Initial Presentation of Systemic Lupus Erythematosus Complicated by Massive Ascites: A Case Report*
}

\author{
Noor Rafhati Adyani Abdullah ${ }^{1}$ and Rosdina Zamrud Ahmad Akbar² \\ ${ }^{1}$ Endocrinology Unit, Department of Medicine, Putrajaya Hospital, Malaysia \\ ${ }^{2}$ Department of Medicine, Universiti Teknologi Mara Medical School, Malaysia
}

\begin{abstract}
Autoimmune thyroiditis in the course of other autoimmune diseases such as systemic lupus erythematosus (SLE) is common because these disorders are attributed to the production of autoantibodies against various autoantigens. Beyond this association, autoimmune thyroiditis can occur before, during or after the development of SLE. In this report, we describe a female who presented with facial puffiness, lethargy and progressive abdominal distension. She was diagnosed with autoimmune thyroiditis followed by the diagnosis of SLE complicated by a massive ascites, a rare form of lupus peritonitis, which is sterile ascites that results from severe serositis. Her presentation was complex and posed a diagnostic challenge and dilemma to the physicians involved in her care.
\end{abstract}

Key words: autoimmune thyroiditis, systemic lupus erythematosus, serositis

\section{INTRODUCTION}

Autoimmune thyroid disease, defined by the presence of antibodies directed against thyroid antigens, is associated with a number of non-organ-specific rheumatological disorders such as systemic lupus erythematosus (SLE). A number of studies have suggested that thyroid disease is more common in SLE than in the general population and the development of thyroiditis can occur before, during or after the diagnosis of SLE. ${ }^{1,2}$ We report a female with autoimmune thyroiditis as the initial presentation of SLE which was complicated by a massive ascites. Her presentation was complex and posed a diagnostic challenge and dilemma to the physicians involved in her care. The ascites was a rare form of lupus peritonitis, with massive ascites that results from severe serositis.

\section{CASE}

A 37-year-old Malay female, presented with facial puffiness, lethargy, reduced effort tolerance and progressive abdominal distension for 3 months. Apart from that, she did not have cold intolerance, weight gain, constipation, reduced cognitive function, slowness or other symptoms of hypothyroidism. At her initial presentation, she had no symptoms to suggest she may have a connective tissue disease such as prolonged fever, arthralgia, photosensitivity, hair loss or oral ulcers. She had normal regular menstruation and there were no constitutional symptoms such as weight loss, poor appetite or night sweats. Systemic symptoms were unremarkable. She had no previous medical problems and she was not on any medications. There was no family history of autoimmune disease. She was married with 3 children who were all well. She was a non-smoker and abstained from alcohol. Her main concern was the extreme lethargy and the abdominal distension which caused significant discomfort. Her waist circumference expanded from $80 \mathrm{~cm}$ to $130 \mathrm{~cm}$ within 3 months. Clinically, she appeared hypothyroid with facial and periorbital puffiness, dry skin and dry hair with a massive ascites (Figures 1 and 2). The heart rate was 60 beats/min with slowly relaxing reflexes. She was pink, had no jaundice, good hydration status, no goitre, no lymphadenopathies, no skin rashes or photosensitivity, oral ulcers, alopecia or other features to suggest autoimmune disease. Thyroid function tests revealed overt primary autoimmune hypothyroidism with TSH $>100 \mathrm{mU} / \mathrm{L}$ (0.34-5.6) and FT4 $4.0 \mathrm{pmol} / \mathrm{L}$ (7.9-14.4) supported by significantly high antiTPO antibody $468.6 \mathrm{U} / \mathrm{ml}(<34)$ and antithyroglobulin antibody $770.4 \mathrm{U} / \mathrm{ml}(<155)$. She was started on levothyroxine replacement, $300 \mathrm{mcg}$ once a day before breakfast for a week in view of the severe hypothyroidism. Her weight at presentation was $60 \mathrm{~kg}$ and the high dose of the initial levothyroxine was administered with a prespecified plan to review her at weekly intervals with repeat thyroid function tests, and further reduction in the levothyroxine dose. The following were her baseline blood investigations (Table 1).
eISSN 2308-118x

Printed in the Philippines

Copyright (C) 2017 by the JAFES

Received: February 13, 2017. Accepted: April 6, 2017.

https://doi.org/10.15605/jafes.032.01.09
Corresponding author: Noor Rafhati Adyani Abdullah, MBBS, MRCP (UK)

Endocrinology Unit, Department of Medicine, Putrajaya Hospital

Precinct 7, 62250 Putrajaya, Malaysia

Tel. No: $+603-83124200$

Fax No.: $+603-88880137$

E-mail: adyania@yahoo.com 


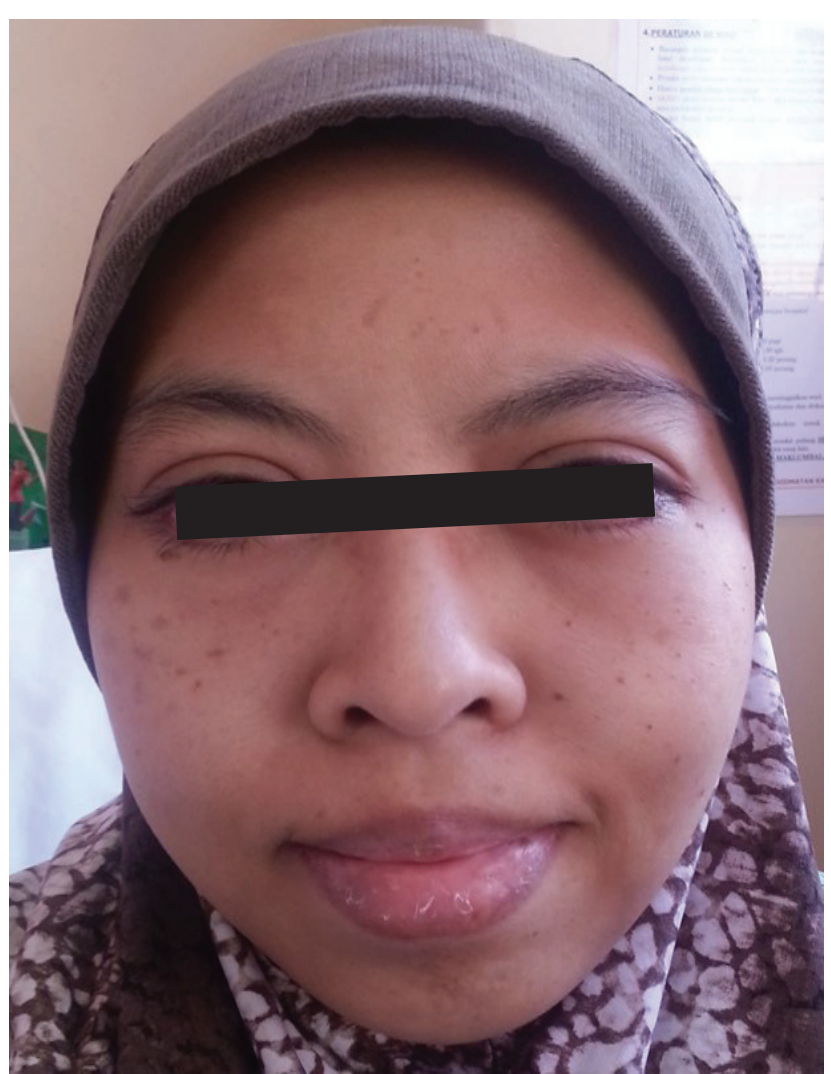

Figure 1. Hypothyroid facies with facial and periorbital puffiness.

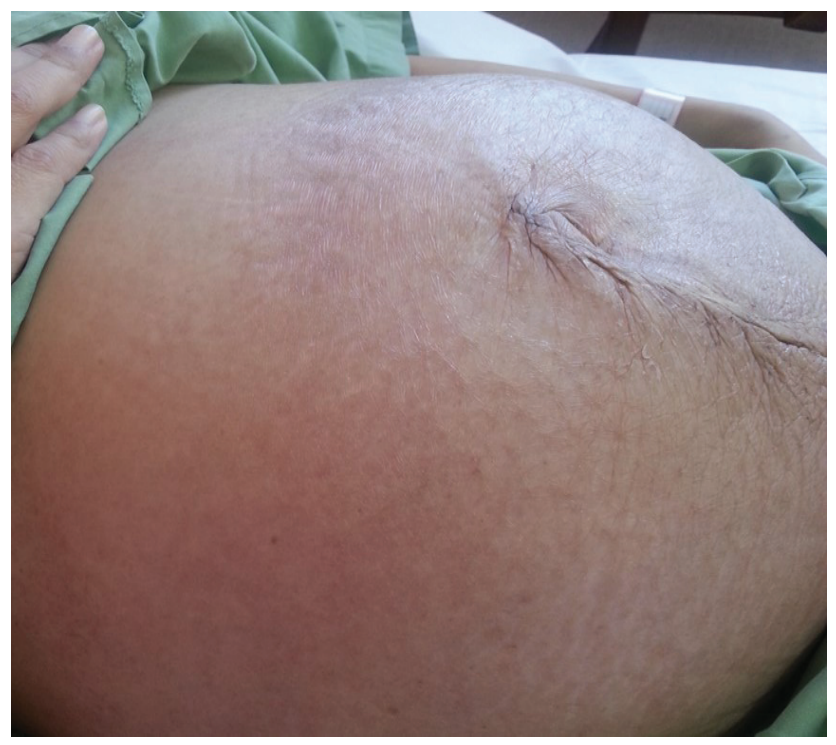

Figure 2. Presence of massive ascites with abdominal girth $120 \mathrm{~cm}$.

Furthermore, she was also noted to have an ovarian mass measuring $5 \times 5 \mathrm{~cm}$ on the transvaginal ultrasound, and the CECT abdomen and pelvis confirmed the presence of a right adnexal mass likely representing an ovarian tumour with pelvic lymphadenopathy. The gynaecologists were concerned about the possibility of ovarian carcinoma. Subsequently, she underwent right salphingectomy, omentectomy, appendicectomy, and right pelvic lymph node sampling. The intraoperative findings were

\begin{tabular}{ll}
\multicolumn{2}{l}{ Table 1. Baseline blood investigations } \\
\hline $\mathrm{Hb}(\mathrm{g} / \mathrm{dL})$ & $10.5(11-16)$ \\
$\mathrm{Hct}(\%)$ & $33.3(37-47)$ \\
$\mathrm{MCV}(\mathrm{fl})$ & $84.1(76-96)$ \\
$\mathrm{MCH}(\mathrm{pg})$ & $26.5(27-32)$ \\
$\mathrm{MCHC}(\mathrm{g} / \mathrm{dL})$ & $31.5(30-35)$ \\
WBC $\left(10^{*} \mathrm{~g} / \mathrm{L}\right)$ & $9.1(4-11)$ \\
Platelets $\left(10^{*} 9 / \mathrm{L}\right)$ & 478 \\
Urea $(\mathrm{mmol} / \mathrm{L})$ & $2.6(1.7-8.3)$ \\
$\mathrm{Na}(\mathrm{mmol} / \mathrm{L})$ & $131(135-145)$ \\
$\mathrm{K}(\mathrm{mmol} / \mathrm{L})$ & $3.5(3.5-5)$ \\
$\mathrm{Creatinine}(\mathrm{umol} / \mathrm{L})$ & $55(44-80)$ \\
Albumin $(\mathrm{g} / \mathrm{L})$ & $22(35-50)$ \\
$\mathrm{fT} 4(\mathrm{pmol} / \mathrm{L})$ & $4(7.9-14.4)$ \\
TSH (mU/L) & $>100(0.34-5.6)$ \\
Anti-TPO $(\mathrm{U} / \mathrm{ml})$ & $468.6(<34)$ \\
Antithyroglobulin $(\mathrm{U} / \mathrm{ml})$ & $770.4(<155)$ \\
\hline
\end{tabular}

oedematous subcutaneous fat, peritoneum and retroperitoneum with normal looking uterus, both ovaries and left fallopian tube. There was a $5 \times 5 \mathrm{~cm}$ right fimbrial cyst (for which cystectomy was done) and normal omentum, mesentery, bowel and liver. Right external and common iliac lymph nodes were enlarged and other lymph nodes were not palpable. All the histopathological specimens from the right fimbrial cyst, omentum, left and right peritoneum, appendix, right external iliac lymph node and right common iliac lymph node were benign tissues and did not contain any malignant cells. The ascitic fluid also did not reveal any malignant cells and contained predominantly lymphocytes, histiocytes, plasma cells and reactive mesothelial cells. Postoperatively she had a very rapid ascitic fluid accumulation associated with pleural effusion and minimal pericardial effusion. The peritoneal fluid was drained by multiple abdominal paracentesis with results of ascitic fluid analyses pointing to an exudative etiology. The tumour markers such as alpha fetoprotein (AFP), CA-125, carcinoembryonic antigen (CEA) and beta human chorionic gonadotrophin (BHCG) were negative. With these clinical evidences of serositis and the presence of autoimmune thyroiditis, a thorough screening for connective tissue diseases was performed (Table 2).

\begin{tabular}{ll} 
Table 2. Connective tissue screening results \\
\hline ANA & reactive $(1: 1280)$, speckled $(1: 5120)$ \\
ENA & positive for SSA/SSB and RNP \\
Direct Coombs & Positive \\
C3 $(\mathrm{g} / \mathrm{L})$ & $0.29(0.83-1.93)$ \\
C4 $(\mathrm{g} / \mathrm{L})$ & $0.07(0.15-0.57)$ \\
Anti-dsDNA & Negative \\
24 hour urine protein & $0.62 \mathrm{~g}(<0.5 \mathrm{~g} /$ day $)$ \\
& Normochromic normocytic anaemia, adequate \\
Full blood picture & white blood cell count,no blast or abnormal \\
& lymphoid cells, reactive thrombocytosis \\
ESR & 111 \\
CRP & 5.8 \\
\hline
\end{tabular}

The fine needle aspiration and cytology of thyroid gland (FNAC) showed lymphoplasmacytic infiltration and few follicles. The follicular epithelium exhibited oncocytic changes consistent with chronic lymphocytic thyroiditis (Hashimoto's thyroiditis).

After 1 month, she started to develop multiple oral ulcers and hair loss. There was mild arthralgia but there was no skin rash or photosensitivity. She was noted to have mild 
nephritis as evidenced by 24-hour urine protein $0.62 \mathrm{~g} / 24 \mathrm{hrs}$ $(<0.5 \mathrm{~g} / 24 \mathrm{hrs})$. Based on the clinical and biochemical manifestations, she satisfied 6 out of 11 criteria for SLE according to the American College of Rheumatology and hence diagnosed as active SLE. She was started on IV methylprednisolone for 3 days followed by hydroxychloroquine and azathioprine. Biochemically, following the levothyroxine replacement, there was a rapid improvement in the thyroid function tests within 2 months and the levothyroxine dose was gradually reduced from 300 mcg to 25 mcg once a day before breakfast (Table 3). She tolerated all the medications well and experienced remarkable improvement with complete resolution of her symptoms following the therapies instituted. The ascites resolved and the facial and periorbital puffiness improved (Figure 3).

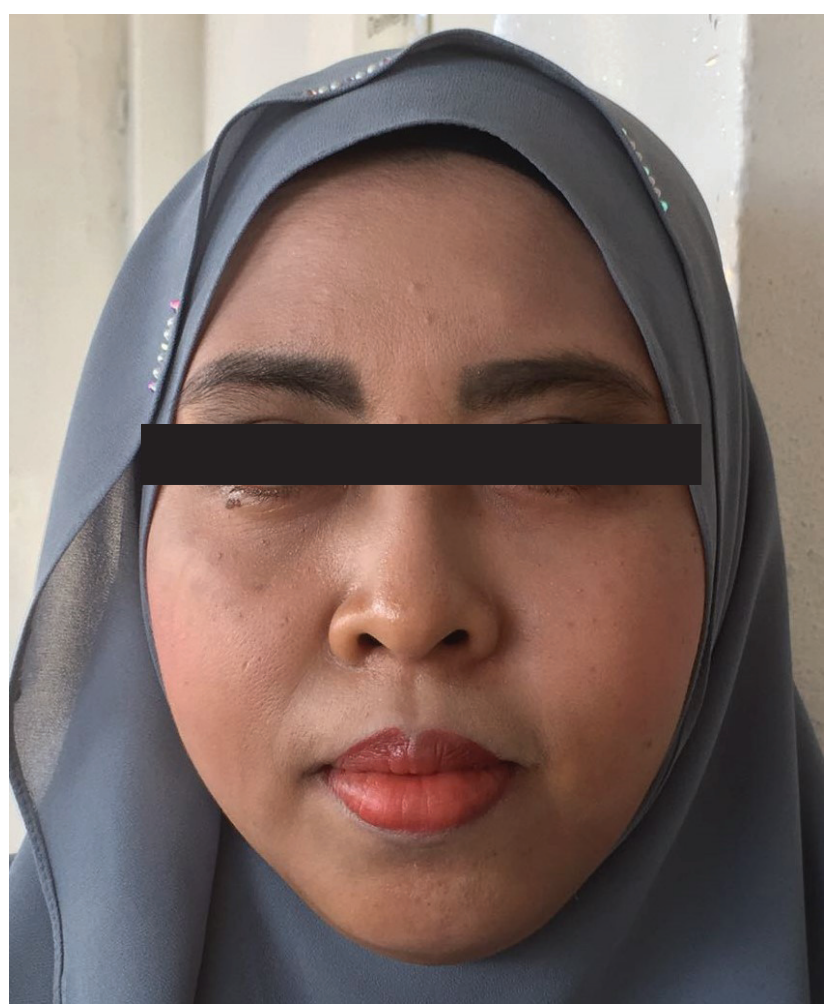

Figure 3. Resolution of periorbital and facial puffiness post treatment.

\section{DISCUSSION}

Approximately 15 to $20 \%$ of patients with systemic lupus erythematosus (SLE) have anti-thyroid antibodies, a higher percentage than is found in normal subjects of the same age. The antibody titres may fluctuate and clinical thyroid disease is associated with the persistent presence of these antibodies. The prevalence of overt thyroid disease appears to be between 3 and 19\%, with subclinical or overt hypothyroidism being more common than hyperthyroidism in most studies. ${ }^{1-3}$ In a study of 153 SLE patients screened for thyroid disease, there was a significant increase in the prevalence of hypothyroidism (19\%), hyperthyroidism (9\%), and thyroid antibodies (33\%) in comparison with controls $(2 \%, 1 \%$, and $13 \%$, respectively). $\cdot^{1-3}$ In a study of 3286 Caucasian subjects with Graves' disease (2791 cases) or Hashimoto's thyroiditis (495 cases), there was a significantly increased relative risk of SLE in both diseases, with the relative risk in women being over 10 -fold. ${ }^{4}$ However, there is limited evidence that the concurrence in the same patient of thyroid disease and connective tissue disease alters the clinical manifestations or natural history of either disorder.

The development of thyroiditis can occur before or after the diagnosis of SLE. In a study of 300 lupus patients, 22 (7\%) had thyroid disease. There were 17 (5.7\%) cases of hypothyroidism; eight were diagnosed before the onset of SLE, six after, and three simultaneously. There were five cases $(1.7 \%)$ of hyperthyroidism, two diagnosed before the onset of SLE and three afterwards. ${ }^{1}$ The development of lupus may be as long as five years later. ${ }^{5}$

SLE is an autoimmune disorder characterized by involvement of various organs. Inflammation of serous membranes including pericardium and pleura is relatively common $(16 \%)$ and accepted by American College of Rheumatology as one of the 11 criteria of SLE. ${ }^{6}$ However, ascites with lupus peritonitis is extremely rare and has only been described in a small group of patients. ${ }^{7,8}$ The mechanism of ascites in SLE may be multifactorial. It is postulated that the deposition of immune complexes in the peritoneum and activation of complements play a crucial role. In addition, vasculitis of peritoneal vessels or the serous membrane of abdominal organs may be related to lupus peritonitis. ${ }^{8}$ Nevertheless, other more common causes of exudative ascites have to be ruled out. On the other hand, in this case, one may think the presence of ascites is most likely due to hypothyroidism instead of lupus peritonitis since the incidence is extremely rare. It is important to note that ascites due to hypothyroidism is transudative rather than exudative.

Ito and associates in a review of chronic lupus peritonitis, reported that in all patients treated with steroids, only $13 / 16$ achieved remissions. In $40 \%$, additional immunosuppressant agents were required to manage incomplete remission and recurrence of ascites. ${ }^{7}$ The strength of the approach to this case was that an accurate diagnosis was made and she was followed up regularly to monitor her symptoms and biochemical parameters. She underwent extensive investigations to ensure the accuracy

\begin{tabular}{|c|c|c|c|c|c|c|}
\hline Date & $27 / 10 / 15$ & $2 / 11 / 15$ & $15 / 11 / 215$ & $30 / 11 / 15$ & $10 / 12 / 15$ & $22 / 12 / 15$ \\
\hline FT4 (pmol/L) & 4 & 14 & 16.7 & 12.5 & 18.3 & 14.1 \\
\hline $\mathrm{TSH}(\mathrm{mU} / \mathrm{L})$ & $>100$ & 16 & 14.9 & 6.25 & 5.4 & 4.74 \\
\hline Levothyroxine dose (mcg/day) & 300 & 150 & 150 & 100 & 50 & 25 \\
\hline
\end{tabular}


of the diagnosis. Hence, appropriate treatments were instituted. The limitation of the approach was a slight delay in diagnosing SLE because of the overlapping symptoms and the concern of malignancy at the beginning resulting in extensive surgeries.

This patient will require life-long monitoring of her thyroid status and adjustment of the thyroid replacement therapy accordingly. There is limited evidence that the presence of both diseases alters the natural history, manifestation or treatment of either disorder. Nevertheless, the concurrence of autoimmune thyroiditis and SLE can pose some risks if she is considering pregnancy. An increased risk of preterm delivery has been noted in pregnant women with SLE and thyroid disease. In a retrospective study of 63 pregnant women with SLE, 37.9 percent of the cohort had thyroid disease diagnosed before, during, or immediately after pregnancy. Preterm delivery occurred in 67 percent of the women who had thyroid disease, compared with 18 percent of the women with SLE who remained free of thyroid disease. Thyroid antibodies did not predict preterm delivery in this group of women. ${ }^{9}$

\section{CONCLUSION}

Thyroid disorders are commonly associated with many autoimmune rheumatic diseases such as SLE and it can occur before or after the diagnosis has been made. It is reasonable to assess thyroid function tests in most patients on presentation and periodically thereafter. In addition, it is important to keep vigilant on the development of SLE following a diagnosis of autoimmune thyroid disease. This case illustrates the importance of early recognition of an atypical presentation of wide spectrum multi-systemic diseases such as SLE with regards to thyroid disorders.

\section{Acknowledgments}

Special acknowledgments to Dr. Zanariah Hussein, Dr Nurain Mohd Noor, Dr Masni Mohamad and Dr. Azraai Bahari Nasruddin from the Endocrinology Unit, Putrajaya Hospital as well as the entire Rheumatology team at the Putrajaya Hospital who have played an instrumental role in the diagnosis and comanagement of this patient.

\section{Ethical Consideration}

Informed consent has been taken before submission of the manuscript.

\section{Statement of Authorship}

All authors certified fulfillment of ICMJE authorship criteria.

\section{Author Disclosure}

The authors have declared no conflict of interest.

\section{Funding Source}

None.

\section{References}

1. Pyne D, Isenberg DA. Autoimmune thyroid disease in systemic lupus erythematosus. Ann Rheum Dis. 2002;61(1):70-2. PMID: 11779764 PMICD: PMC1753864.

2. Appenzeller S, Pallone AT, Natalin RA, Costallat LT. Prevalence of thyroid dysfunction in systemic lupus erythematosus. J Clin Rheumatol. 2009; 15(3):117-9.PMID:19300286. https://doi.org/10.1097/ RHU.0b013e31819dbe4c.

3. Vianna JL, Haga HJ, Asherson RA, Swana G, Hughes GR. A prospective evaluation of antithyroid antibody prevalence in 100 patients with systemic lupus erythematosus. J Rheumatol. 1991;18(8):1193-5. PMID: 1941823.

4. Boelaert K, Newby PR, Simmonds MJ, Holder RL, Carr-Smith JD, Heward JM, et al. Prevalence and relative risk of other autoimmune diseases in subjects with autoimmune thyroid disease. Am J Med. 2010;123(2):183.e1-9. PMID: 20103030. https://doi./org/10.1016/ j.amjmed.2009.06.030.

5. Dhir R, Ahluwalia AI, Sridhar J, Mani H, Pruthi HS, Shah KM. Autoimmune thyroiditis predating the presentation of systemic lupus erythematosus: Two cases and a review of literature. Indian J Dermatol Venereol Leprol. 2002;68(5):292-4. Available from: http:// www.ijdvl.com/text.asp?2002/68/5/292/12499

6. Hochberg MC. Updating the American College of Rheumatology revised criteria for the classification of systemic lupus erythematosus. Arthritis Rheum. 1997;40(9):1725. PMID: 9324032. https://doi.org/ 10.1002/1529-0131(199709)40:9\&lt;1725::AID-ART29\&gt;3.0.CO;2-Y.

7. Hammami S, Bdioui F, Ouaz A, Loghmari H, Mahjoub S, Saffar H. Successful treatment of massive ascites due to lupus peritonitis with hydroxychloroquine in old-onset lupus erythematosus. Pan Afr Med J. 2014;18:165. PMICID: PMC4239444. https://doi.org/10.11604/ pamj.2014.18.165.2080.

8. Pott Júnior H, Amate Neto A, Teixeira MA, Provenza JR. Ascites due to lupus peritonitis: A rare form of onset of systemic lupus erythematosus. Rev Bras Reumatol. 2012;52(1):116-119. PMID: 22286651.

9. Stagnaro-Green A, Akhter E, Yim C, Davies TF, Magder L, Petri M Thyroid disease in pregnant women with systemic lupus erythematosus: Increased preterm delivery. Lupus. 2011;20(7):690-9. PMID: 21436215. https://doi.org/10.1177/0961203310394894.

\footnotetext{
Authors are required to accomplish, sign and submit scanned copies of the JAFES Author Form consisting of: (1) Authorship Certification, that all the requirements for authorship have been met by each author, and that the final version of the manuscript has been read and approved by all authors; (2) the Author Declaration, that the article represents original material that is not being considered for publication or has not been published or accepted for publication elsewhere; (3) the Statement of Copyright Transfer [accepted manuscripts become the permanent property of the JAFES and are licensed with an Attribution-Share Alike-Non-Commercial Creative Commons License. Articles may be shared and adapted for non-commercial purposes as long as they are properly cited]; and the ICMJE form for Disclosure of Potential Conflicts of Interest. For original articles, authors are required to submit a scanned copy of the Ethics Review Approval of their research as well as registration in trial registries as appropriate. For manuscripts reporting data from studies involving animals, authors are required to submit a scanned copy of the Institutional Animal Care and Use Committee approval. For Case Reports or Series, and Images in Endocrinology, consent forms, are required for the publication of information about patients; otherwise, authors declared that all means have been exhausted for securing such consent. Articles and any other material published in the JAFES represent the work of the author(s) and should not be construed to reflect the opinions of the Editors or the Publisher.
} 